\title{
Message from the new Editor-in-Chief
}

\author{
Naoto Ebuchi ${ }^{1}$
}

Published online: 15 April 2019

(c) The Oceanographic Society of Japan and Springer Nature Singapore Pte Ltd. 2019

As of April 1, 2019, I will become the new Editor-in Chief of the Journal of Oceanography, taking over from Dr. Joji Ishizaka. I would like to express my sincere appreciation to Dr. Ishizaka and the 22 previous editorial board members for their great contributions to the Journal of Oceanography. Seven of the previous editorial board members will be replaced by new members, and we are also seeking additional editorial members outside of Japan to enhance our handling capability.

The Journal of Oceanography is becoming one of the leading international journals focusing on the western North-Pacific and Asian marginal seas. Over the last 4 years, there have been more than 100 submissions per year from 33 countries. Approximately, 50 scientific papers have been published every year including short contributions, review articles and special issues. Many of the recent papers are published only 6 months after submission.
As the new Editor-in-Chief, I am looking forward to seeing many high-quality papers in oceanography. Our interests are not limited to the western North Pacific and its marginal seas, but also extended to the world Oceans and Seas, from coast to offshore. We also would like to invite review papers to summarize the current understandings of the field and special issues of specific topics and to discuss future directions. We welcome your ideas and suggestions for further improvement of the Journal of Oceanography.

Naoto Ebuchi

Editor-in-Chief

Naoto Ebuchi

ebuchi@lowtem.hokudai.ac.jp

1 Hokkaido University, Sapporo, Japan 